\title{
Circular Green Technology \& Material for the Tire Industry
}

\author{
Elamvazhuthi Kuppusamy ${ }^{\mathrm{a}, 1}$ \\ a CEO \& Director Operations, Tyromer India LLP, Chennai, Tamilnadu, India
}

\begin{abstract}
The whole Tire Industry around the Globe is set on an important mission to create a greener environment wherein the used tires, scrap worn out tires \& shop floor rejected tires are used back in to the system of new Tire manufacturing thereby create a Circular Economy in the Tire Industry via nonchemical Devulcanization process. The Tyromer TDP ( Tyre Derived Polymer ) production process uses an industrial proven extrusion technology in a patented Twin Screw Extruder and it is reliable. The process is energy efficient as it is continuous. That also gives fundamentally more consistent product quality compared to batch processes.
\end{abstract}

In this extrusion process, what goes in must come out and hence the TDP production process creates no waste. The only catalyst used in the process is Super Critical Carbon dioxide. No chemical solvents or devulcanization chemicals are used and the process is Energy efficient $(400 \mathrm{kWh} / \mathrm{MT})$, Very Fast $(2$ minutes from crumb powder to TDP) and having High conversion rate $(99+\%$ crumb powder to TDP).

Keywords. Tyromer, Tire Derived Polymer( TDP), Devulcanization, Extrusion Technology, Super Critical CO2, Crumb Powder, Circular Green Technology, discarded tires, Circular Economy

\section{Introduction}

The mission is to create a truly circular economy in the tire industry using the chemical-free devulcanization process. With all the issues surrounding global warming, water supply, fires, and pollution in general, it's truly believed that it is important to take steps towards a brighter future. Return scrap tire rubber to new tires.

\section{Disadvantages of discarded tires:}

These discarded tires carriage serious environmental and health issues such as:

1) piles of the waste tires generate vermin and insect infestation, posing a severe health issue;

\footnotetext{
${ }^{1}$ Corresponding Author. drkelamvazhuthi@gmail.com
} 
2) piles of waste tires may catch fire, re-resulting in a fire that is hard to extinguish and that generates hazardous gases, heavy metals, and oil that severely contaminate the soil, environment, and groundwater; and

3) waste tires require large landfills and an increasing number of discarded tires may lead to landfill maintenance issues.

4) cross-linked structure and the presence of various additives
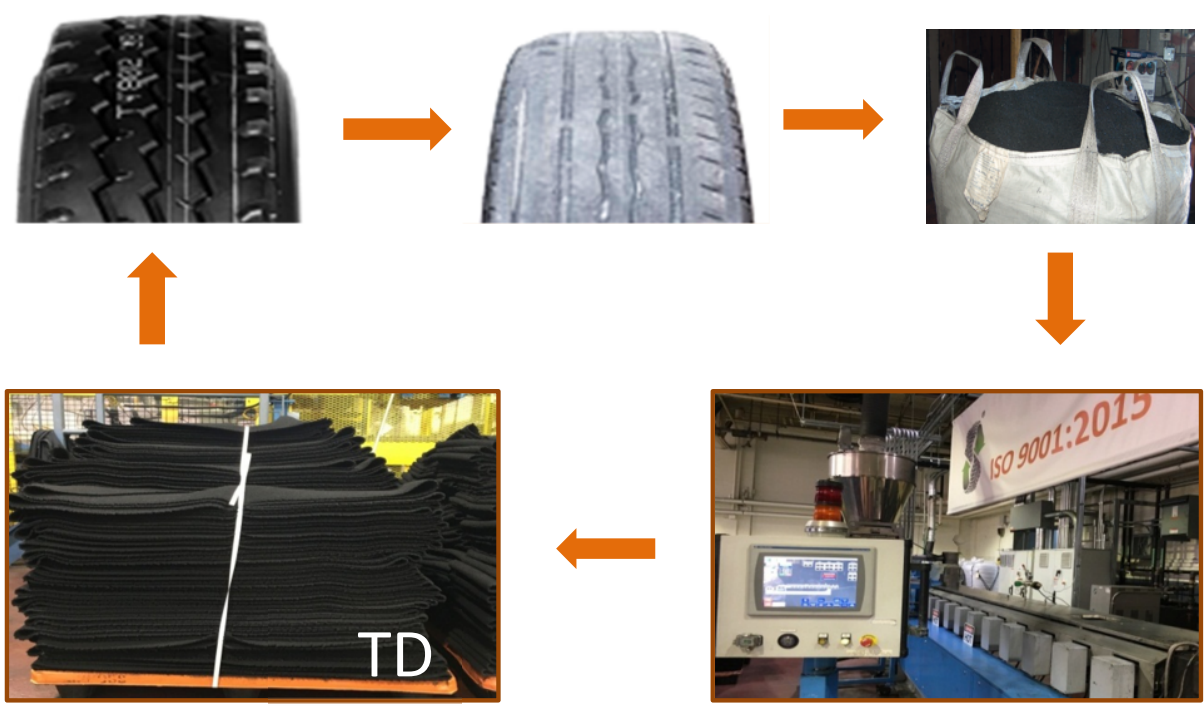

Figure 1. TDP Production Cycle from Waste Tyre

\section{Why to Recycle Old Off The Road Tire (OTR)?}

Examples of OTR: wheel loaders, backhoes, graders, trenchers, on airplanes, on mining vehicles, on forestry machinery

- Dramatically increasing commodity prices has led to shortages of new tires. Leads to costing mines millions of dollars in lost productivity. Led to a stronger effort to recycle old OTR tires.

- Higher cost of new OTR tire

- Retread tires are sold at half the price of new tires. Retreading an OTR tire is labor-intensive.

- As the world population increases, the number of vehicles is expected to increase from 1.2 billion to 2 billion by 2035 . This results in the production of nearly 1.5 billion tires per year, which inevitably turn into waste. 


\section{Why to Devulcanize?}

With devulcanization, 10-30\% recycled waste tire rubber and in some cases more, can be reused in new tires with excellent results. Devulcanization presents the largest opportunity and highest added value for waste tires, enabling a circular economy and cutting down significantly on the amount of resources consumed in making new tire rubber.

Tyromer's devulcanization technology is the only proven global solution to return ELT rubber back into tires at meaningful levels.

Tyromer's focus is to devulcanize ELT rubber for reuse in rubber products in an environmentally sustainable and financially viable way as a socially responsible solution to the massive global ELT problem.

\section{An Introduction on Tyromer:}

The technology was invented at the University of Waterloo in Canada, and since 2009 Tyromer has been working to scale up and commercialize the technology. Using a licensing business model so that Tyromer can supply almost anywhere in the world, and the core strategy revolves around open innovation and collaboration.

Tyromer consider themselves the world leaders in non-chemical devulcanization. The technology is proven to work at commercially viable scale. They have been long-time proponents of recycled material in the tire industry and have over 10 years of experience with devulcanization of different rubbers with the technology. While Tyromer understand that there are many barriers to entry for a small company, they work diligently to find solutions that benefit everyone involved.

\section{Technology}

Tyromer devulcanization technology was invented by Professor Tzoganakis of the University of Waterloo, and he still leads Tyromer Canada R\&D program as Chief Technology Officer. 2 years ago he was given one of the most prestigious awards in polymers, the James L White Award, by the Polymer Processing Society for his invention.

10 years ago, the technology was invented on a lab scale. Since then have scaled up and commercialized the technology. Our standard line can run continuously at about $700 \mathrm{~kg}$ /hour, and our process is very environmentally friendly. Low power consumption, no devulcanization chemicals or solvents used, no additives, and no solid waste created.

\section{About TDP (Tire-Derived Polymer)}

- TDP replaces master batch compound

- Can be produced in any form

- $\quad$ TDP can be made from variety of feedstock 
- $\quad$ Truck tires

- Whole passenger tires

- $\quad$ Factory scrap

- $\quad$ TDP used for 4 years in tire industry

- Replaces $20 \%$ of master batch material

- $\quad$ TDP is approved for use in new PLT and TBR tires, as well as new OTR tires and retreads by multiple global companies

\section{TDP in Tire Industry}

Kal Tire is Canada's largest independent tire dealer and one of North America's largest commercial tire dealers. Kal Tire's Mining Tire Group is a global leader in mining tire service and supply, servicing more than 150 mine sites across five continents. The company services over $250 \mathrm{Kal}$ Tire retail and commercial stores.

Kal Tire owns and operates five earthmover retreading facilities located in Canada, the United Kingdom, West Africa and Chile

"Blending 20\% of TDP into our rubber tread compound provides a high-quality product that performs in OTR applications just as well as our regular tread compound." ( KAL Tire https://www.kaltire.com/en/responsibility-retreading/ )

Air Boss (ON Canada) sells a tire compound with 20\% TDP for OTR retreading. KAL Tires, global OTR retreaders uses this compound in its operation.

\begin{tabular}{|c|c|c|c|c|c|c|}
\hline & Control & & $20 \%$ TDP & & & \\
\hline & & Drop -In & $\mathbf{A}$ & B & C & D \\
\hline Tensile (Mpa) & 21 & 20 & 20 & 18 & 19 & 19 \\
\hline Elongation at Break (\%) & 520 & 460 & 470 & 460 & 450 & 430 \\
\hline Hysteresis (Deg F) & 47 & 41 & 38 & 35 & 34 & 38 \\
\hline Blow-Out Minutes & 3.4 & 4 & 4.6 & 5.4 & 4.9 & 3.7 \\
\hline Cut and Chip: Mass Loss (\%) & 13 & 14 & 14 & 11 & 11 & 10 \\
\hline Cut and Chip: Dia Loss (\%) & 15 & 17 & 17 & 12 & 12 & 11 \\
\hline DIN Abrasion & 154 & 156 & 137 & 155 & 152 & 146 \\
\hline
\end{tabular}

Table 01. Use of TDP in an OTR Tread Compound typically reduces hysteresis, Blow-out minutes, Cut \& Chip. TDP In TYRE COMPOUND 


\section{Application of Tyromer TDP}

Tyromer TDP is master batch replacement material with excellent dynamic properties, making it ideally suited for the tire industries. Tyromer TDP with Superior abrasion resistance performance - great for the mining industry. Tyromer TDP is environmentally sustainable. Tyromer TDP is cost effective. Tire production: Passenger Truck, OTR solid, agriculture, Mining, Non-vehicle Tires. Retreading: truck, OTR, solid tires

To date TDP has been used at the $20 \%$ level in OTR and agriculture tires, and in passenger and truck tires in the near future. TDP has been approved for use in new OTR tires by one of the largest OTR tire and track manufacturers. A 10,000 MT TDP Production Plant is being built to supply this customer.

\section{Tyromer TDP vs. Reclaimed Rubber}

\begin{tabular}{|c|c|c|c|}
\hline \multicolumn{3}{|c|}{ Report No / Date : RCCPLL / 11-19 / 009} & \multirow[t]{2}{*}{$\mathrm{Dt}: 2$} \\
\hline \multicolumn{3}{|c|}{ Customer sample ref : Trial 1} & \\
\hline Test (Condition) & Unit & Test Method & Observed Values \\
\hline \multicolumn{4}{|l|}{$\frac{\text { Mooney viscosity }}{\text { ML (1+4)@100C }}$} \\
\hline $\mathrm{ML}(1+4) @ 100 \mathrm{C}$ & MU & ASTM D 1646 & 24.3 \\
\hline \multirow{2}{*}{\multicolumn{4}{|c|}{\begin{tabular}{|l} 
Rheo properties \\
\end{tabular}}} \\
\hline & & & \\
\hline \multicolumn{3}{|l|}{$\begin{array}{l}\text { ODR @150 } 150^{\circ} \mathrm{C}, 3 \mathrm{Arc} \\
\mathrm{M}_{1} \text { Min. Torque } \\
\end{array}$} & \\
\hline \begin{tabular}{|l|}
$M_{L}$ Min. Torque \\
$M_{n}$ Max. Torque \\
\end{tabular} & Ib.in & \begin{tabular}{|l|} 
ASTM D 2084 \\
ASTM D 2084
\end{tabular} & $\begin{array}{l}18.8 \\
67.6\end{array}$ \\
\hline \begin{tabular}{|l}
$M_{n}$ Max. Torque \\
TS2
\end{tabular} & $\min$ & \begin{tabular}{|l|} 
ASTM D 2084 \\
ASTM D 2084
\end{tabular} & $\begin{array}{l}67.6 \\
2.0\end{array}$ \\
\hline \begin{tabular}{|l|} 
TS2 \\
Tc'90 \\
\end{tabular} & $\min$ & $\begin{array}{l}\text { ASTM D 2084 } \\
\text { ASTM D 2084 }\end{array}$ & 5.6 \\
\hline & & & \\
\hline Tensile Strength & Mpa & ASTM D 412 & 10.1 \\
\hline Elongation @ break & $\%$ & ASTM D 412 & 305 \\
\hline Hardness & Shore A & ASTM D 2240 & 53 \\
\hline Modulus $100 \%$ & $\%$ & ASTM D 412 & 1.9 \\
\hline Modulus 200\% & $\%$ & ASTM D 412 & 5.1 \\
\hline \multicolumn{4}{|c|}{ *EQSEND OF REPORTQAQA } \\
\hline
\end{tabular}

TDP is made with no chemical additives, no devulcanization chemicals or solvents, process creates no solid waste

Reclaimed rubber $\sim 3 \%+$ chemicals by weight

Tyromer India proposed facility capacity is 4,000 MT/year

Using 4,000 MT of TDP instead of reclaim saves: $4,000 * .03=120 \mathrm{MT}$ of chemicals saved. 


\begin{tabular}{|c|c|c|c|}
\hline Grades & $\begin{array}{l}\text { High Tensile } \\
\text { Reclained Rubber } \\
\text { HTR-604 }\end{array}$ & $\begin{array}{l}\text { High Tensile } \\
\text { Reclaimed Rubber } \\
\text { HTR-704 }\end{array}$ & $\begin{array}{l}\text { Superfine } \\
\text { WTR -5504 } \\
\text { / BRI-504 }\end{array}$ \\
\hline Physical Appearance & Black Slab & Black Slab & Black Slab \\
\hline CHEMICAL PROPERTIES & & & \\
\hline $\begin{array}{l}\text { Acetone - extract \% } \\
\text { Ash \% } \\
\text { Carbon black \% } \\
\text { RHC \% } \\
\text { Volatile Matter \% }\end{array}$ & $\begin{array}{r}14 \pm 3 \\
7 \pm 2 \\
26 \pm 3 \\
\operatorname{Min} 47 \\
<1\end{array}$ & $\begin{array}{r}14 \pm 3 \\
7 \pm 2 \\
26 \pm 3 \\
\operatorname{Min} 47 \\
<1\end{array}$ & $\begin{array}{c}14 \pm 2.5 \\
7 \pm 2 \\
25 \pm 3 \\
\text { Min } 47 \\
<1\end{array}$ \\
\hline PHYSICAL PROPERTIES & & & \\
\hline $\begin{array}{l}\text { Specific Gravity } \\
\text { Tensile Strength } \\
\mathrm{Kg} / \text { Sq.om } \\
\text { Elongation } \% \\
\text { Hardness Shore "A" } \\
\text { Mooney Viscosity } \\
\text { L (1+4)@ } 100^{\circ} \mathrm{C}\end{array}$ & $\begin{array}{c}\text { Max } 1.15 \\
\text { Min } 60 \\
\text { Min } 230 \\
60 \pm 5 \\
40-60\end{array}$ & $\begin{array}{c}\text { Max } 1.15 \\
\text { Min } 70 \\
\text { Min } 250 \\
60 \pm 5 \\
40-60\end{array}$ & $\begin{array}{c}1.12 \pm 0.02 \\
\text { Min } 40 \\
\\
\text { Min } 200 \\
60 \pm 3 \\
30-55\end{array}$ \\
\hline
\end{tabular}

\section{Conclusion}

Tyromer TDP is one of the valuable products invented for bringing the circular Green Economy in Tire production. Tyromer India has already ventured into commercial execution of the Project in India with Technical Collaboration from Tyromer Canada. It has already tied with one of the prestigious Institutions of Repute Madras Institute of Technology( MIT), Chennai to offer technical and R\&D support, till the facilities are established in the plant. Besides, it has already received letter of Interest from the leading Tires manufacturing companies in India viz., Apollo Tires and MRF Tires and also the leading OTR Tires making plant ATG Tires in Tamilnadu. Besides, R\&D Trials are being carried out in the leading conveyor belt manufacturing company, Forech Conveyor Belts Ltd in Chennai. We hope to commercially launch the Tyromer TDP in Indian Market by end of 2021.

\section{Acknowledgements}

The author kindly acknowledges the Promoters of Tyromer India LLP and Tyromer Canada Inc and Prof. Dr. Tzoganakis, Tyromer Technology Inventor and Chief Technology Officer for their involvement and guidance to publish this paper.

\section{References}

[1] Reference: Tyromer Canada Inc, website : https://tyromer.com 